\title{
Role of binder in the synthesis of titania membrane
}

\author{
K S SESHADRI*, M SELVARAJ ${ }^{\dagger}$, R KESAVA MOORTHY ${ }^{\ddagger}$, K VARATHARAJAN ${ }^{\ddagger}$, \\ M P SRINIVASAN** and $\mathrm{K}$ B LAL \\ Centralised Waste Management Facility, **Water and Steam Chemistry Department, Bhabha Atomic Research \\ Centre Facility, Kalpakkam 603 102, India \\ ${ }^{\dagger}$ Anna University, Chennai 600 025, India \\ ${ }^{\ddagger}$ Materials Science Department, Indira Gandhi Centre for Atomic Research, Kalpakkam 603 102, India
}

MS received 20 April 2002; revised 25 October 2002

\begin{abstract}
The synthesis of titania membrane through sol-gel route involves hydrolysis of alkoxide, peptization of hydrous oxide of titanium to obtain a sol, adjustment of the sol viscosity by including a binder and filtration of the viscous sol through a microporous support, gelation and sintering to desired temperature. The binder plays an important role in that it not only helps in adjustment of sol viscosity but also helps in binding the sol particle with porous support. Here a comparative study on the role of different binders, viz. polyvinyl alcohol, polyethyleneimine, polyacrylamide, effect of their viscosity and surface tension effect on the morphology of the titania membrane is presented. The results show that among the three binders studied polyvinyl alcohol gave rise to membranes of desired characteristics when the sol viscosity was 0.08 pa.s.
\end{abstract}

Keywords. Alkoxide; viscosity; surface tension; binders; morphology.

\section{Introduction}

Membrane separation techniques are very attractive and in many cases are faster and more efficient than conventional processes, as the fractionation takes place without a phase change. There are several routes to synthesize inorganic membranes like anodic oxidation, thin film deposition, track-etch, sol-gel etc. The sol-gel route involves filtration of viscous sol through microporous support, gelation and sintering (Larbot et al 1989). The viscosity of the sol is conditioned by inclusion of a binder. Hence the selection of binder plays a dominant role in the synthesis of the membrane. Binders are used to allow the adjustment of sol viscosity and protect thin layer from cracking during sol-gel transition at drying stage. Nitrogen containing groups, hydroxyl and methylol, promote adhesion to inorganic and organic adherent. Based on these criteria, polyvinyl alcohol, polyacrylamide and polyethyleneimine were chosen as binders (Souhenge 1982).

\section{Experimental}

AR grade titanium tetrabutoxide, Merck-Schuchardt (Germany) make was used as the precursor material. AR grade polyvinyl alcohol, polyethyleneimine and polyacrylamide all procured from Merck-Schuchardt (Germany)

*Author for correspondence were chosen as binders for the study. The viscosity of the sol was determined by measuring the power associated with the rotation of paddle agitator of make Remi Udyog, Mumbai, within the laminar region using glycerol as standard (Shingji 1975) and the corresponding viscosity is presented in table 1 as a function of concentration expressed in wt\%. The surface tensions of the binders at various concentrations were measured using a torsion balance (M/s Hardson, Kolkata). The surface morphology of the membranes was studied using scanning electron microscope (Ims camaca-4f, Psem-501, The Netherlands).

To evaluate the binding capacity of different binders with porous support, the IR frequency shift in the functional group of the binder when bonded to the support was studied (Nakamoto 1977). 0.08 pa.s viscous solutions of the polyvinyl alcohol, polyacrylamide and polyethyleneimine were filtered separately through the porous support for $30 \mathrm{~min}$ at $5 \mathrm{~kg} / \mathrm{cm}^{2}$ using the filtration set up. It consists of a small mild steel tank of 11 capacity closed at the top with three holes, one for connecting the nitrogen gas cylinder for pressurization, the second for a pressure gauge and the third for introducing the sol for filtration. The fittings were made air tight to avoid any pressure leakage. The coated surface was dried at $100^{\circ} \mathrm{C}$, cooled to room temperature and the IR spectra (Model 270-30, Hitachi, Japan) were recorded. The IR spectra of the binders with and without support are shown in figure 1 .

Hydrous oxide of titanium was prepared by the hydrolysis of titanium tetrabutoxide which was peptized in nitric acid medium at $\mathrm{pH}=1 \mathrm{using} 10^{-3} \mathrm{M}$ sodium nitrate as stabilizing electrolyte. To find out the effect of visco- 
sity on the surface morphology of the membrane, the sol viscosity was adjusted to 0.08 pa.s by including $3.8 \mathrm{wt} \%$ or $0.069 \mathrm{wt} \%$ or $25 \mathrm{wt} \%$ of the polyvinylalcohol, polyacylamide or polyethyleneimine, respectively. The above three sols were filtered through the porous support for 35 min using the above described filtration set up. The sols were gelled at $20^{\circ} \mathrm{C}$ and then sintered at $400^{\circ} \mathrm{C}$ since phase transitions of the amorphous titania to anatase phase was reported to occur at this temperature. The membranes thus formed were examined by scanning electron microscope (make Ims camaca-4f, Psem-501, The Netherlands). The SEM micrographs of the titania membranes prepared using these binders are shown in figure 2 and the pore size distribution from these SEM is shown in figure 3.

To find out the effect of viscosity and surface tension of the binders in the $300 \mathrm{ppm}$ titania sol, polyvinyl alcohol of concentration $0.765 \mathrm{wt} \%, 1.826 \mathrm{wt} \%, 3 \mathrm{wt} \%$ and $3.8 \mathrm{wt} \%$ were included giving rise to viscosity of $0.05-$ 0.08 pa.s. The viscous titania sols were filtered through the porous support for $35 \mathrm{~min}$, gelled and sintered at $400^{\circ} \mathrm{C}$. The sintered titania membrane was examined by SEM. The micrographs are shown in figure 4 and the corresponding pore size distributions are shown in figure 5.

\section{Results and discussion}

\subsection{IR spectra}

From figure 1 we observe that polyvinyl alcohol has free $-\mathrm{OH}$ band at $3500 \mathrm{~cm}^{-1}(3.5 \mu \mathrm{m})$ in free state. When it is bonded to alumina support, the $-\mathrm{OH}$ band of the polyvinyl alcohol decreases to $3472 \mathrm{~cm}^{-1}(2.88 \mu \mathrm{m})$ giving rise to negative shift of $28 \mathrm{~cm}^{-1}$ in the band position. The bonding between the electron pair available on the $-\mathrm{OH}$ group of the polyvinyl alcohol to the support decreases the bond strength of the $-\mathrm{OH}$ group of the polyvinyl alcohol. This results in the negative IR frequency shift of the functional group - $\mathrm{OH}$ of polyvinyl alcohol.

Polyethyleneimine shows -NH stretching band at $3355 \mathrm{~cm}^{-1}(2.98 \mu \mathrm{m})$ in the free state. It decreases to

Table 1. Variation of viscosity of binders with concentration.

\begin{tabular}{lccc}
\hline $\begin{array}{l}\text { Viscosity } \\
(\mathrm{cp})\end{array}$ & $\begin{array}{c}\text { Polyvinylalcohol } \\
(\mathrm{wt} \%)\end{array}$ & $\begin{array}{c}\text { Polyacrylamide } \\
(\mathrm{wt} \%)\end{array}$ & $\begin{array}{c}\text { Polyethyleneimine } \\
(\mathrm{wt} \%)\end{array}$ \\
\hline 50 & $0 \cdot 765$ & $0 \cdot 051$ & $6 \cdot 7$ \\
60 & $1 \cdot 826$ & $0 \cdot 059$ & $14 \cdot 0$ \\
70 & $3 \cdot 000$ & $0 \cdot 064$ & $23 \cdot 0$ \\
80 & $3 \cdot 800$ & $0 \cdot 069$ & $25 \cdot 0$ \\
\hline
\end{tabular}

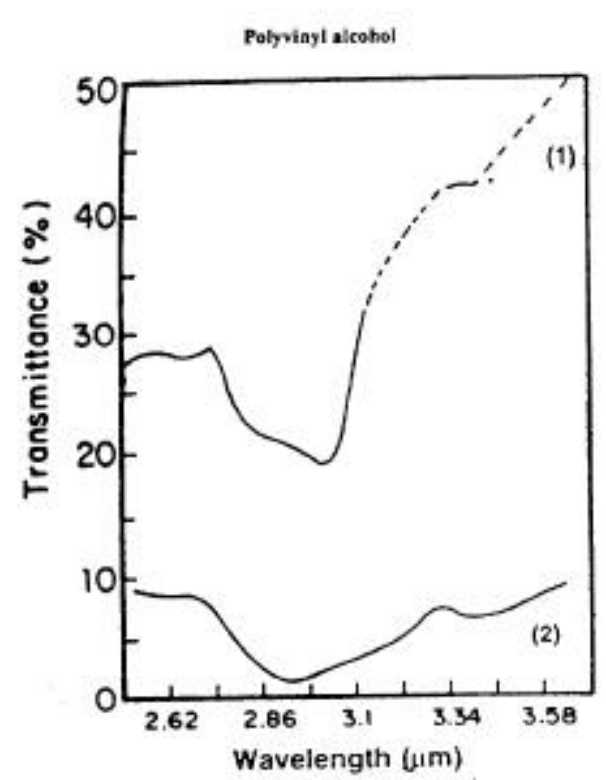

(1) with support

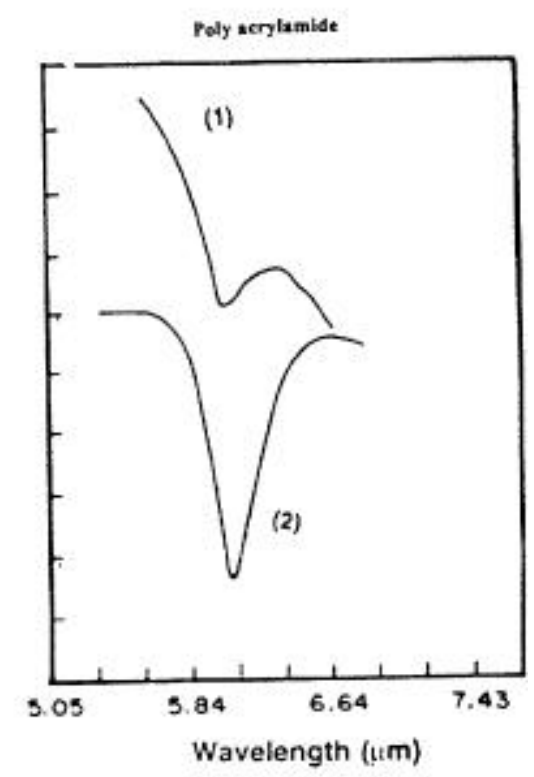

(2) without support

Figure 1. IR spectra of binders with and without the porous support. 

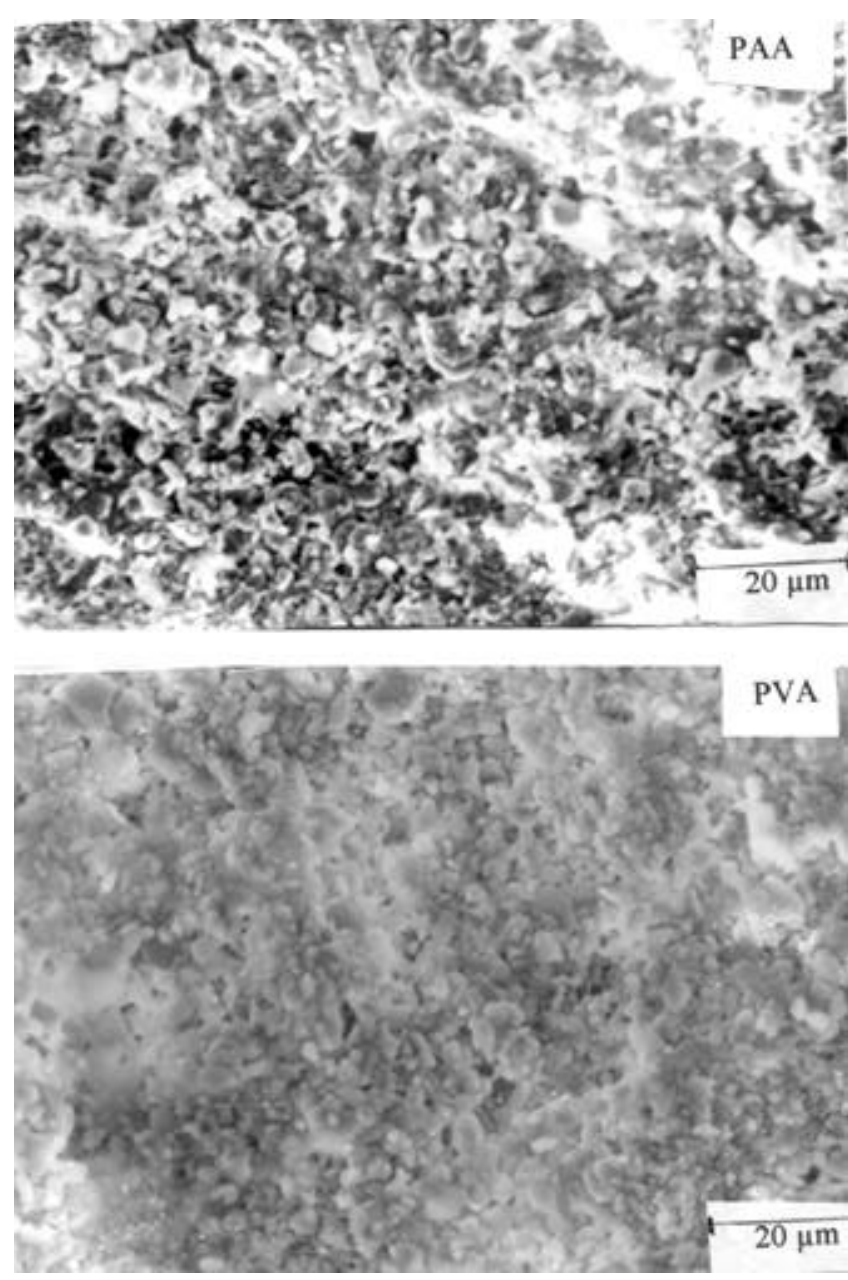

Figure 2. Scanning electron micrographs of titania membranes formed using different binders.

$3333 \mathrm{~cm}^{-1}(3.0 \mu \mathrm{m})$ when bonded to alumina support. This results in the negative shift of $22 \mathrm{~cm}^{-1}$ in the band position. The electron pair available on the nitrogen of the imino group in polyethyleneimine bonding to the support decreases the bond strength of the imino group. This results in the negative IR frequency shift of the functional group $-\mathrm{NH}$ of the polyethyleneimine. Polyacrylamide shows carbonyl absorption band at $1650 \mathrm{~cm}^{-1}$ $(6 \mu \mathrm{m})$ giving rise to positive shift of $16 \mathrm{~cm}^{-1}$ in the band position. The bonding of the electron pair available on the nitrogen of the amide group is reflected in the IR frequency of the carbonyl group of the binder (when bonded to alumina support) in the positive direction. Since among the binders polyvinyl alcohol shows highest frequency shift, it is expected to show the best binding to the alumina support because of the relatively larger interactions. The frequency shift is attributed to the coordination between the oxygen of the $-\mathrm{OH}$ group present in the alcohol to the metal atom of the oxide in the support. Considering the magnitude of the frequency shift, polyvinyl alcohol was chosen as the binder for further studies.

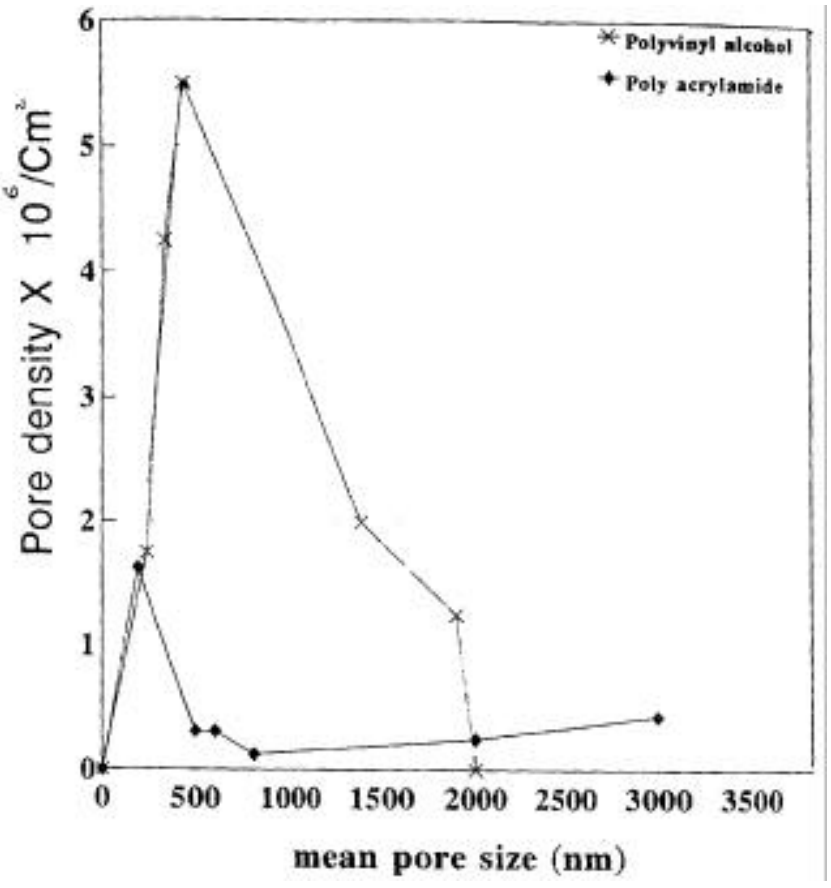

Figure 3. Pore size distribution of titania membrane formed using different binders.

\subsection{Effect of surface tension of the binder}

Low energy materials having surface tension below 100 dynes/cm (organic polymers and water) tend to adsorb strongly onto high energy surfaces having surface tension in the range 200-5000 dynes/cm (e.g. oxides, nitride, silica and diamond) as this will greatly decrease the surface energy of the system (Smith 1962).

For polymeric binders, adhesion is a two-stage process, wetting as the first stage followed by interdiffusion (Smith 1962). Hence a binder with low surface tension in the solution is preferable for good adhesion. The surface tension in dynes/cm of the polyvinyl alcohol, polyacrylamide and polyethyleneimine varied between 58 and 45,65 and 62, and 59 and 52, respectively in the viscosity range $0.06-0.08$ pa.s. It is clear from these measurements that polyvinyl alcohol has low surface tension. Hence polyvinyl alcohol was preferred as binder.

\subsection{Effect of nature of the binder}

Various authors have reported that polyvinyl alcohol undergoes two stages of decomposition (Suchiya and Sumi 1969), the first at $240^{\circ} \mathrm{C}$ with the formation of water and carbonyl compound as the main decomposition product. The second stage of decomposition takes place at $300^{\circ} \mathrm{C}$ with a series of $n$-alkanes, $n$-alkenes and aromatic hydrocarbons. Polyacrylamide undergoes three stages of weight loss (Mark et al 1985a), the first stage is due to loss of ammonia at $290^{\circ} \mathrm{C}$, the second stage at $430^{\circ} \mathrm{C}$ with loss 

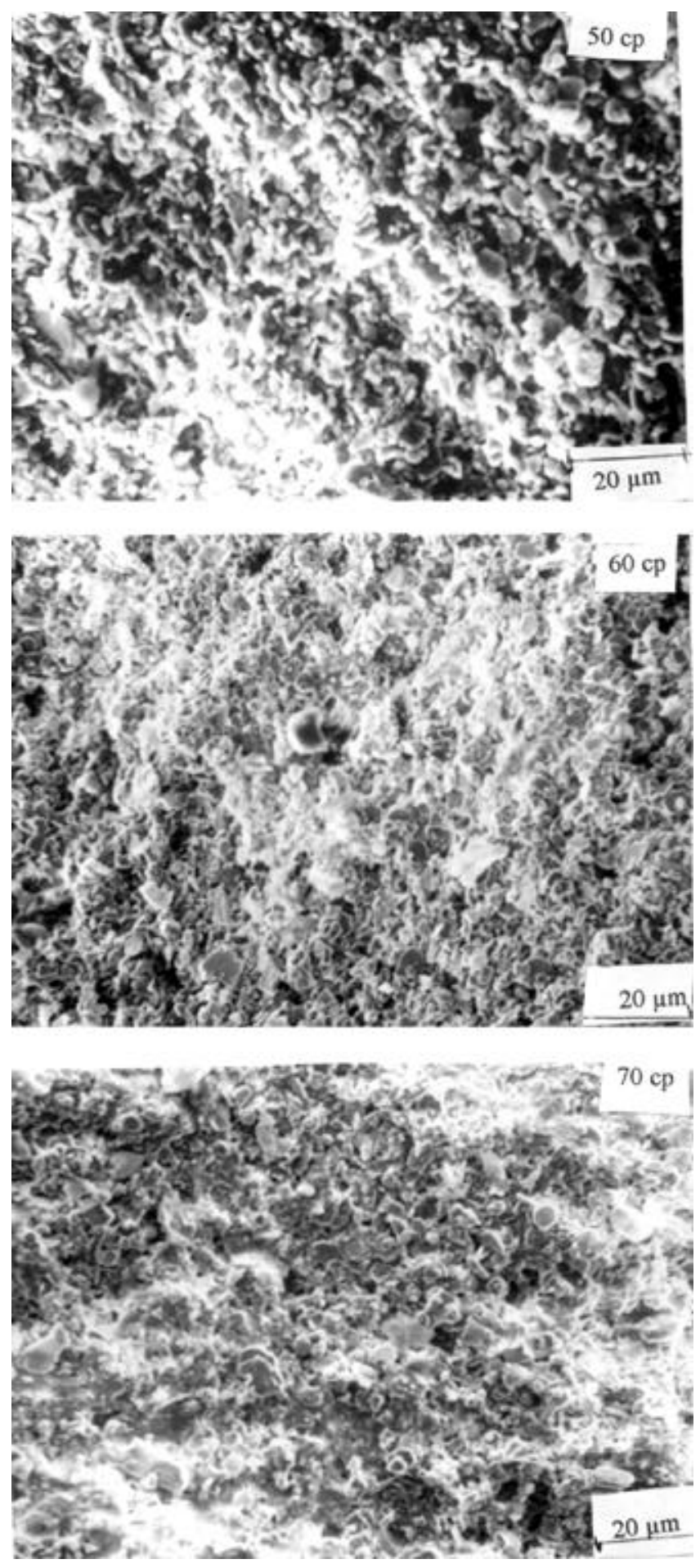

Figure 4. Scanning electron micrographs of titania membranes formed at different viscosities of polyvinyl alcohol.

of water, carbon monoxide and ammonia and the third stage at $550^{\circ} \mathrm{C}$ also with the loss of the above materials. The losses at the three stages taken together are to the extent of $98.5 \%$ by wt. Decomposition of polyethyleneimine (Mark et al 1985b) does not occur below $300^{\circ} \mathrm{C}$. In the membrane prepared using polyethyleneimine as

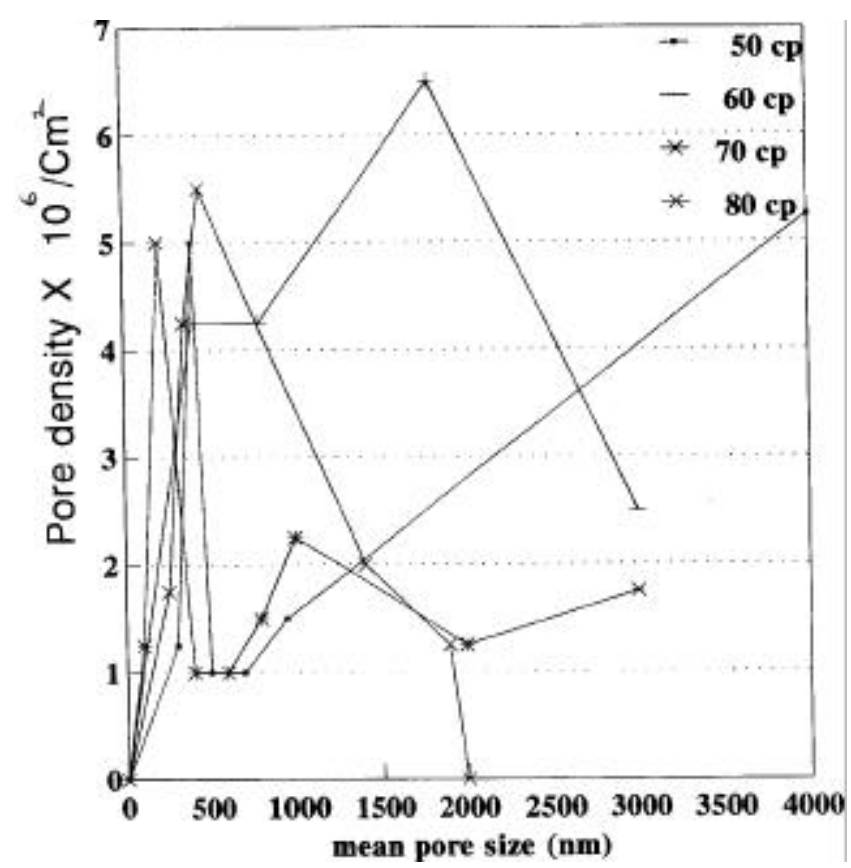

Figure 5. Pore size distribution of titania membrane formed at different viscosities of polyvinyl alcohol.

binder the pores are covered with the binder due to its incomplete removal. Hence the pore size of the membrane prepared using polyethyleneimine as binder could not be estimated. Also it is observed that pore size reduction is more with polyvinyl alcohol than with polyacrylamide. From figures 2 and 3 we find that the mean pore size of the titania membrane prepared using polyvinyl alcohol and polyacrylamide are $650 \mathrm{~nm}$ and $725 \mathrm{~nm}$, respectively. The surface tension of the binder at the same viscosity i.e. 0.08 pa.s was found to follow the order polyvinyl alcohol < polyethyleneimine < polyacrylamide. The relatively less surface tension of the polyvinyl alcohol indicates that its wettability on the support is more. The greater IR frequency shift using polyvinyl alcohol corroborates this also.

\subsection{Effect of viscosity}

From the SEM and pore size distribution (figures 4 and 5 ), we observe that the mean pore size decreases with increase in viscosity of the sol. The mean pore size of the titania membrane were $1455 \mathrm{~nm}, 1395 \mathrm{~nm}, 725 \mathrm{~nm}$ and $650 \mathrm{~nm}$, from the sol of viscosities $0.05,0 \cdot 06,0.07$ and 0.08 pa.s, respectively. This result indicates more particles underwent binding with the support with increase in viscosity. The increase in viscosity was accompanied by a decrease in the surface tension of the binders. The surface tension corresponding to the sol viscosities of 0.05 , $0.06,0.07$ and 0.08 pa.s were $70,63,53$ and 44 dynes $\mathrm{cm}^{-1}$, 
respectively. The decrease in surface tension facilitated more wetting of the binder with consequent adhesion of the membrane material with the support.

\section{Conclusion}

Tailor made titania membranes could be prepared using sol-gel route by adjusting the wt\% of the binder which takes care of the viscosity and surface tension of the sol.

\section{Acknowledgements}

The authors express their thanks to S Ramachandran and $S$ Kathiresan for their help in the experimental work and Smt Vijayalakshmi for the SEM analysis.

\section{References}

Larbot Andre, Fabre Jean-Paul, Guizard Christian and Cot Lois 1989 J. Am. Ceram. Soc. 72257

Mark, Bikales, Overberge and Menges 1985a Encyclopedia of polymer science and engineering (New York: John-Wiley and Sons) Vol. 1 pp169-203

Mark, Bikales, Overberge and Menges 1985b Encyclopedia of polymer science and engineering (New York: John-Wiley and Sons) Vol. 17 pp 767-792

Nakamoto K 1977 Infrared and Raman spectra of inorganic and coordination compounds (New York: John-Wiley and Sons)

Shingji Nagata 1975 Mixing, principles and applications (Kodansha Ltd, Tokyo: Ahalsted Press Book)

Souhenge W U 1982 Polymer interface and adhesion (New York: Marcel Dekker)

Smith T A 1962 Trans. Br. Soc. 61523

Tsuchiya Y and Sumi K 1969 J. Polym. Sci. 73151 